\title{
Preparedness of Hospitals in North of Iran to Deal With Disasters
}

\author{
Mohammad Amiri ${ }^{1}$, Reza Chaman ${ }^{2}$, Mehdi Raei ${ }^{3,{ }^{*},}$ Seiyed Davoud Nasrollahpour Shirvani ${ }^{4}$, \\ Abolhasan Afkar ${ }^{5}$ \\ ${ }^{1}$ Health Services Management, School of Public Health, Shahroud University of Medical Sciences, Shahroud, IR Iran \\ 2 Department of Community Medicine, School of Medicine, Shahroud University of Medical Sciences, Shahroud, IR Iran \\ 3 Department of Biostatistics, School of Medicine, School of Medicine, Qom University of Medical Sciences, Qom, IR Iran \\ 4 Department of General Education, Babol University of Medical Sciences, Babol, IR Iran \\ 5 Department of General Education, Babol University of Medical Sciences, Babol, IR Iran \\ ${ }^{*}$ Corresponding author: Mehdi Raei, Department of Biostatistics, School of Medicine, School of Medicine, Qom University of Medical Sciences, Qom, IR Iran. Tel: +98-9122473070, Fax: \\ 98-2517832470, E-mail:mehdi_r_d@yahoo.com.
}

Received: January 28, 2012; Revised: December 10, 2012; Accepted: May 10, 2013

\begin{abstract}
Introduction:Preparedness of hospital has a major impact on their optimal and satisfactory performance. This study aimed to investigate the preparedness of the hospitals to deal with disasters.

Case Presentation: This cross-sectional study was carried in 2011 and all of the hospitals which were located in the northern areas of Iran were investigated through the census method. The data collection instruments were self-administered Managers' Awareness Questionnaire (40 items) and a 141-item checklist. The mean percentage score of hospitals in management of the unanticipated disasters program in the hospital was good. The mean score of managers' awareness of the hospital status was moderate. With the increase in managers' awareness, the preparedness of the hospitals significantly increased $(\mathrm{r}=0.73, \mathrm{P}<0.001)$.

Conclusions: The findings showed the moderate preparedness of the hospitals in the Northern provinces to deal with disasters.
\end{abstract}

Keywords: Iran; Disasters; Hospital Preparedness

\section{Introduction}

Throughout its ancient history, Iran has witnessed a great many natural and non-natural disasters and in this regard, it is ranked fourth in Asia and sixth worldwide (1). Although only $1 \%$ of the world's population live in Iran, more than $6 \%$ of world's natural disasters occur there (2) and because of being located in Alps-Himalayas Seismic zone, Iran is one of the top 10 countries vulnerable to earthquakes and in fact it is one of the regular victims of quakes (3). Though rare, disasters have destructive effects and they expose the health care system to multitude of patients and casualties. These effects even last long after the crisis (4). Moreover, efficient management of hospitals and healthcare centers can have a constructive role in their optimal and satisfactory performance in crises (5).

Results of a study in hospitals in Tehran indicate the average preparedness of hospitals to deal with disasters (3, $6)$. In another study carried out in Kermanshah, the preparedness of teaching hospitals of this province to deal with crises have been reported poor (7). With regard to these issues, the present study intended to determine the level of preparedness of some Iranian hospitals in dealing with disasters.

\section{Case Presentation}

In this cross-sectional study, all hospitals $(n=53)$ of five provinces of Semnan, Golestan, Mazandaran and Gilan were investigated through census method. The data collection instruments included a self-administered Managers' Awareness Questionnaire (40 items), and a 141 item checklist which includes eight domains of Assessment of Environmental Health Measures (16 items), Managing Unanticipated Events in Hospital (12 items), Planning and Support for Vital Services (17 items), Hospital Educational Program for Dealing with Disasters (18 items), Planning Safety of Equipment and Hazardous Materials in Disasters (26 items), Reducing Construction Dangers (8 items), Planning for Evacuation and Field Treatment (20 items), Planning for Necessary Medical and Nonmedical Equipment and Consumables (16 items) and 8 general items which were completed by the managers of the hospitals(self -assessment) based on the documents. The reliability of the questionnaire was examined through

Implication for health policy/practice/research/medical education

Throughout its ancient history, Iran has witnessed a great many natural and non-natural disasters and in this regard, it is ranked fourth in Asia and sixth worldwide. With regard to these issues, the present study intended to determine the level of preparedness of some Iranian hospitals in dealing with disasters.

Copyright (C) 2013, Iranian Red Crescent Medical Journal; Licensee Kowsar Ltd. This is an Open Access article distributed under the terms of the Creative Commons Attribution License (http://creativecommons.org/licenses/by/3.0), which permits unrestricted use, distribution, and reproduction in any medium, provided the original work is properly cited. 
test-retest method and Pearson correlation was found to be 0.91 . SPSS 13 was used to analyze the data through ManWhitney and Kruskal Wallis tests. To investigate the correlation, the Pearson correlation was used. In this study, the confidence level was $95 \%$ and the significance level was 0.05 .

$41.5 \%$ of the respondents had bachelor's degrees, $17 \%$ had master's degrees and $39.7 \%$ had PhD or were general practitioners. $45.3 \%$ of respondents majored in nursing, $37.7 \%$ majored in medicine, and $17 \%$ majored in other fields such as management of healthcare services, environmental health or laboratory sciences. $64.2 \%$ of respondents had work experience less than 10 years, $32.1 \%$ had $10-20$ years of experience, and 3.8\% had over 20 years of experience. 58.5\% of the managers stated that they had been trained on disaster management and $96.2 \%$ of managers stated their need for educational and refreshment courses in this regard. In general, 35.8\% (n $=19)$ of hospitals had weak preparedness, $54.4 \%(n=25)$ had moderate preparedness, and 9.4\% ( 5 ) had good preparedness. Mean percentage score of hospitals in the domain of managing unanticipated events in hospitals was good, and in scopes including planning support for vital services, safety of equipment and hazardous materials in disasters, necessary medical and nonmedical equipment and consumables was moderate and in other scopes including hospital educational program, environmental health measures, reducing construction dangers, and evacuation and field treatment was weak (Table 1).

\begin{tabular}{|c|c|}
\hline Scopes of Preparedness & Mean \pm SD \\
\hline $\begin{array}{l}\text { Managing Unanticipated Events in Hos- } \\
\text { pital }\end{array}$ & $77.36 \pm 22.25$ \\
\hline $\begin{array}{l}\text { Hospital Educational Program for Dealing } \\
\text { with Disasters }\end{array}$ & $44.76 \pm 26.20$ \\
\hline Support of Vital Services & $72.91 \pm 19.65$ \\
\hline Environmental Health Measures & $47.46 \pm 26.77$ \\
\hline $\begin{array}{l}\text { Safety of Equipment and hazardous Mate- } \\
\text { rials in Disasters }\end{array}$ & $61.75 \pm 15.55$ \\
\hline Reducing Construction Dangers & $40.56 \pm 29.4$ \\
\hline Evacuation and Field Treatment & $42.92 \pm 21.43$ \\
\hline $\begin{array}{l}\text { Necessary Medical and Nonmedical Equip- } \\
\text { ment and Consumables }\end{array}$ & $65.09 \pm 28.26$ \\
\hline General Preparedness & $56.88 \pm 15.12$ \\
\hline
\end{tabular}

The mean score of managers' awareness of hospital conditions was $41.89 \pm 9.12$ which shows the moderate awareness of the managers. With the increase in managers' awareness scores, the preparedness of hospitals significantly increased $(\mathrm{P}<0.001, \mathrm{r}=0.73)$. In general, 35.8\% of hospitals had poor preparedness and more than half of the managers (85.7\%) were not adequately trained in disaster management. No significant difference was observed between the average preparedness score and work experience of the manager $(P=0.21)$, gender $(P=0.63)$, manager's education $(P=0.17)$ and manager's field of study $(\mathrm{P}=0.06)$ (Table 2$)$.

Table 2. Relationship Between Hospital Preparedness and Some Variables

\begin{tabular}{|c|c|c|c|}
\hline & No. & Mean \pm SD & P value \\
\hline \multicolumn{4}{|c|}{ Manager's Experience } \\
\hline$<10$ years & 34 & $73.03 \pm 18.15$ & 0.27 \\
\hline 10-20 Years & 17 & $82 \pm 23.01$ & \\
\hline$>20$ years & 2 & $66.5 \pm 24.74$ & \\
\hline \multicolumn{4}{|l|}{ Manager's gender } \\
\hline Male & 44 & $76.09 \pm 19.41$ & 0.63 \\
\hline Female & 9 & $73.56 \pm 24.45$ & \\
\hline \multicolumn{4}{|c|}{ Manager's education } \\
\hline Bachelor's and less & 23 & $76.61 \pm 18.1$ & 0.17 \\
\hline Master's & 9 & $86 \pm 25.25$ & \\
\hline $\mathrm{PhD}$ or GP & 21 & $70.19 \pm 18.87$ & \\
\hline \multicolumn{4}{|c|}{ Manager's Field of Study } \\
\hline Nursing & 24 & $76.71 \pm 22.27$ & 0.06 \\
\hline Medicine & 20 & $68.2 \pm 16.94$ & \\
\hline Management & 2 & $87 \pm 4.24$ & \\
\hline Others & 7 & $90.14 \pm 14.66$ & \\
\hline
\end{tabular}

There was a significant relationship between training on disasters and manager's awareness $(\mathrm{P}=0.007)$, but no significant relationship was observed between training and general preparedness of the hospital $(\mathrm{P}=0.8)$.

\section{Discussion}

According to findings of this study; $15.1 \%$ of managers had no training on dealing with disasters. Other studies reported the number of untrained managers to be $6.7 \%$ and $13 \%$ and in some areas even $47.6 \%$ and $73 \%(3,6$, $8,9)$. Neither were there significant relationships between the preparedness of the hospital and the manger's age, experience in management, education, field of study and training to deal with disasters. Hosseini also reported similar results (7). Preparedness of hospitals in managing unanticipated events in hospital and supporting vital services was assessed to be rather good which is close to the findings of other studies $(6,10)$. In this study, the mean percentage of hospital preparedness in reducing the construction dangers was less than that of other domains. The poor building status of hospital in this domain in all other studies carried out in Iran is consistent with this finding $(6,8,10)$. Hospital preparedness in the domain of educational planning on dealing with disasters was weak. This is consistent 
with the findings of other studies $(7,8,11)$. However, this finding is not consistent with the findings of the study by Top and colleagues in Turkey and Cliff in the United States, which showed the good preparedness of hospitals in this domain $(11,12)$.

\section{Conclusions}

The findings indicate that the hospitals in the northern provinces of the country, have moderate preparedness to deal with disasters. Organizing educational programs on dealing with disasters, developing educational programs for hospital personnel and strengthening hospital buildings and organizing practice maneuvers can play an effective role in increasing hospital preparedness to deal with disasters.

\section{Acknowledgements}

This study was approved of by the research councils of Shahroud, Babol and Guilan universities of medical sciences (No 8845). The researchers extend their gratitude to all managers and authorities in these universities for their financial and official support in carrying out this research.

\section{Authors' Contribution}

None declared.

\section{Financial Disclosure}

There is no financial disclosure.

\section{Funding Support}

There is no funding or support.

\section{References}

1. Mohebbifar R, Tabibi SJ, Asefzadeh SAEID. Designing a Structure of Disaster Management for Iran. J Health Admin. 2008;11(33):47-56.

2. Jahangiri K, Tabibi SJAD, Maleki Mohammar Reza, AlamdarI SH. A comparative study on community-based disaster management $(\mathrm{cbdm})$ in selected countries and proposing a model for iran. Payesh. 2009.

3. Arab M, Zeraati H, Akbari Haghighi F, Ravangard R. A study on the executive managers' knowledge and performance, and their hospitals preparedness against earthquake events and their relationships at public hospitals (affiliated by Tehran University of Medical Sciences) (2005-2006). If Health Admin. 2009;11(34):7-14.

4. World Health Organization. Rapid Health Assessment Protocols for Emergencies. Ministry of Health \& Medical Education Health Subcommittee for Natural Disasters Reduction \& WHO press; 2001.

5. Maleki M, Khoshkam M, Shojaee P. Preparation Aspects of Supplies Provision Encounter Disasters in Selected Hospitals of Iran University of Medical Sciences. Health Inform Management. 2008;5(1).

6. Ojaghi Shahnaz, Nourizad Samad, Mahboobi Mohammad, Khazaei MohammadRasool, Najafi Ghodratollah. Disaster crisis handling preparedness level of hospitals in Kermanshah. Journal of Kermanshah University of Medical Sciences. 2009;13(3)

7. Hoseini S. Evaluation of Hospital Preparation under Iran University of Medical Sciences to earthquake: Tehran University of Medical Sciences; 2008.

8. Mohabbati F. Evaluation of Knowledge, attitude and directors of the hospitals affiliated to Tehran University of Medical Sciences earthquake: Tehran University of Medical Sciences; 2004.

9. Ebrahimpour H, Dehnavieh R, Jaefari M. Assessment of readiness of public hospitals in Iran university to deal with disasters. 2 rd International Congress on Health, Medication and Crisis Management in Disaster. Tehran: Shakrvi press; 2004. p. 309.

10. Arab M. Comprehensive model for hospitals during the crisis, 2 rd International Congress on Health. Medication and Crisis Management in Disaster. Tehran: Shakrvi press; 2004.

11. Top Mehmet, Gider Ömer, Tas Yunus. An Investigation of Hospital Disaster Preparedness in Turkey. Journal of Homeland Security and Emergency Management. 2010;7(1).

12. Cliff BJ, Morlock L, Curtis AB. Is there an association between risk perception and disaster preparedness in rural US hospitals? Prehosp Disaster Med. 2009;24(6):512-7. 